\title{
Urachal Tumor: Mucinous Gystadenoma of Undetermined Malignant Potential
}

\section{SC Hiremath ${ }^{1}$, SI Neeli ${ }^{1}$, MB Hiremath ${ }^{2}$, Shridhar $\mathbf{G}^{2}$}

From the Department of Urology', KLE University's JN Medical College and

KLES Dr Prabhakar Kore Hospital Belgaum; Department of Biotechnology and Microbiology ${ }^{2}$, Karnatak University Dharwad; India.

\section{Abstract:}

Urachal malignancy is a rare and represents less than one percent of bladder neoplasms. Urachal mucinous neoplasms are still rare and include both villous adenomas and invasive adenoma carcinomas and they have insidious course and variable clinical presentation. We present a case report of 58 year old male who presented with lower abdominal mass since 6-8 months with no lower urinary tract symptoms, significant history of loss of weight and appetite. On examination the infra-umbilical midline mobile mass of $10 \times 10$ cms was palpable. CT showed lobulated cystic mass with internal septations and calcifications superior to bladder with indentation and without any local or distant metastasis. Mass was excised in toto with partial/ segmental cystectomy. Histology revealed mucinous cystadenoma of undetermined malignant potential, rarest histological variety and difficult to diagnose on basis of mucin histochemistry and immunohistology. Two-year follow-up did not show any local tumor recurrence.

Key words: Adenoma, Mucinous Cystadenoma, Urinary Bladder Neoplasms, Urachus, Male.

\section{Introduction}

The urachus, an embryological structure extending from the umbilicus to the urinary bladder apex persists uncommonly in adults [1]. Rarely, the urachus may be the primary site of benign and malignant neoplasms. Urachal malignancy is a rare and represents less than $1 \%$ of bladder neoplasms [2]. Urachal mucinous neoplasms are still rare and include adenoma, adenocarcinoma. It has insidious course and variable clinical presentation. We present a case report of 58 years old male patient who presented with lower abdominal mass and histology revealed mucinous cyst adenoma of undetermined malignant potential. This has rarely been described in the literature and should be treated similarly to their benign counterparts; with complete surgical excision to prevent local tumor recurrences [3].

\section{Case Report}

A 58 year old male patient presented with lower abdominal mass associated with dull aching pain. The patient had no irritative urinary symptom and specifically had no gross hematuria or mucusuria.

\section{Corresponding Author: Dr. SC Hiremath}

Email: dr.schiremath@rediffmail.com

Received: June 24, 2014 | Accepted: August 20, 2014 | Published Online: September 20, 2014

This is an Open Access article distributed under the terms of the Creative Commons Attribution License (creativecommons.org/licenses/by/3.0)

Conflict of interest: None declared | Source of funding: Nil | DOl: http://dx.doi.org/10.17659/01.2014.0089 
Patient had recent history of loss of weight and appetite with no other clinical co-morbidity. Examination revealed firm, vertically oval infraumbilical mass of $10 \times 10 \mathrm{cms}$. No organomegaly, or free fluid was noted in the abdominal cavity. All hematological and biochemical study results were within normal limits. Ultrasonography of abdomen and pelvis revealed thin walled multicystic lesion measuring $8 \times 7 \times 6 \mathrm{cms}$ arising from dome of the bladder [Fig.2]. Computer tomography revealed lobulated cystic mass $8 \times 6 \mathrm{cms}$ with internal septations and intra-mural calcification resting antro-superiorly to bladder causing mild indentation with minimal peripheral enhancement [Fig. 1a,b]. Fat plane between mass and superior wall of the bladder was lost with maintenance of fat planes between rectus and adjacent bowel loop. No pelvic lymphadenopathy and no liver metastasis were seen.

Lower midline incision was given and patient underwent resection of mass in toto, including entire urachus with partial cystectomy. Mass was totally free from the surrounding structure but inferiorly it was communicated with dome of bladder,

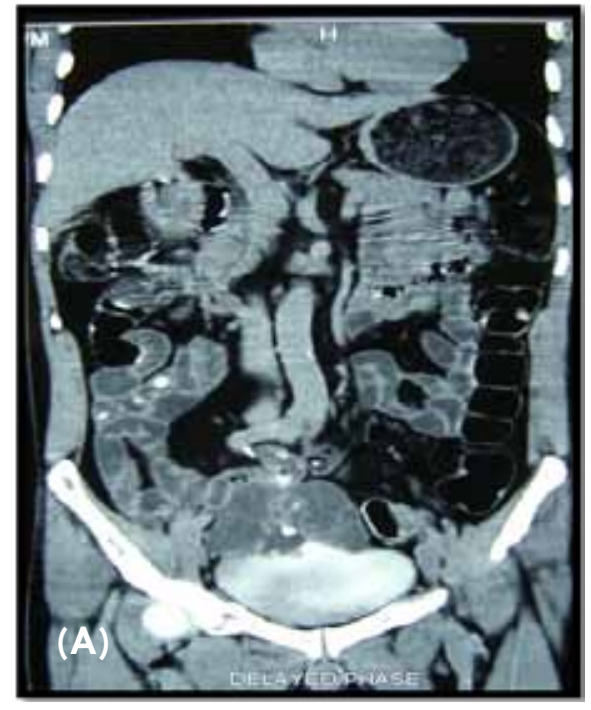

umbilicus was free [Fig.3,4]. There is no evidence of psuedomyxoma peritonei, no pelvic nodes, and liver showed normal features. Postoperative period was uneventful. Pelvic drain was removed on $2^{\text {nd }}$ day and skin sutures were removed after 10 days. Histopathology revealed, the urachus was lined by transitional epithelium beneath which there was loose connective tissue, muscle bundle, fibroareolar tissue at places, cyst were lined by columnar epithelium, which showed multilayering and moderate degree of atypia [Fig.5].

A year after the patient was well with no evidence of local recurrence or distant metastasis.

\section{Discussion}

The urachus is an embryological structure extending from the umbilicus to the urinary bladder apex and it uncommonly persists in adults [4]. The urachus connects the bladder with the allantois in fetus. In normal development, the allantois is gradually reduced and obliterated. Then urachus becomes a fibrous band extending from the anterior bladder dome to the umbilicus. Urachal tumors usually remain

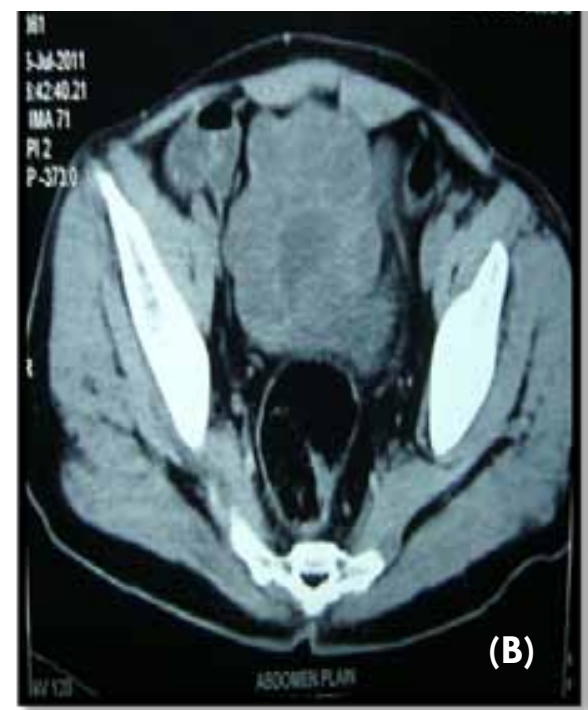

Fig.1 a,b: Computer tomography revealed lobulated cystic mass with internal sepataions and intra-mural calcification resting antro-superiorly to bladder causing mild indentation. 


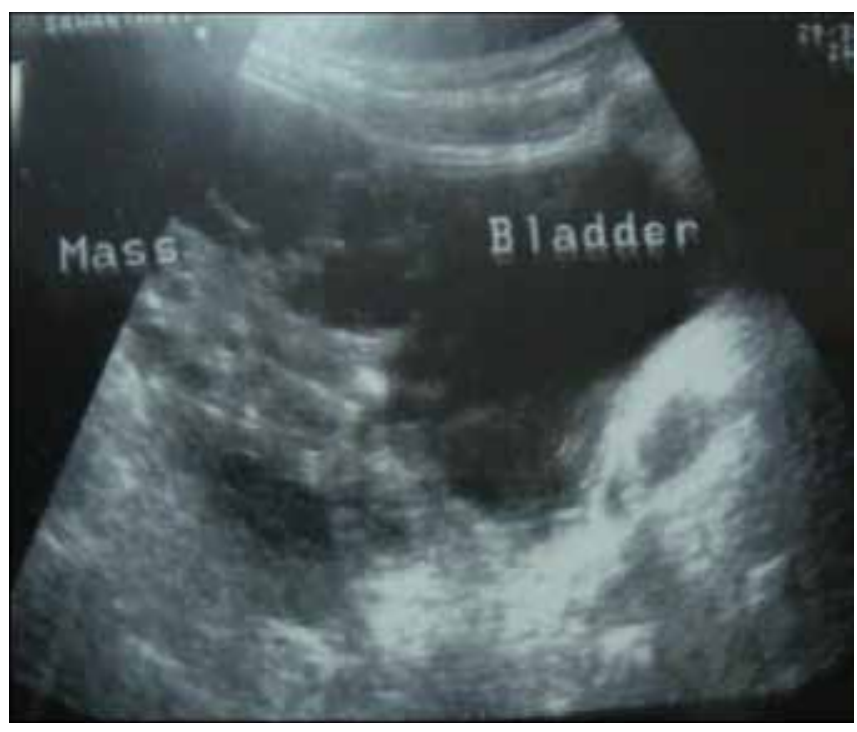

Fig.2: Ultrasonography of abdomen and pelvis revealed thin walled multicystic lesion arising from dome of the bladder.

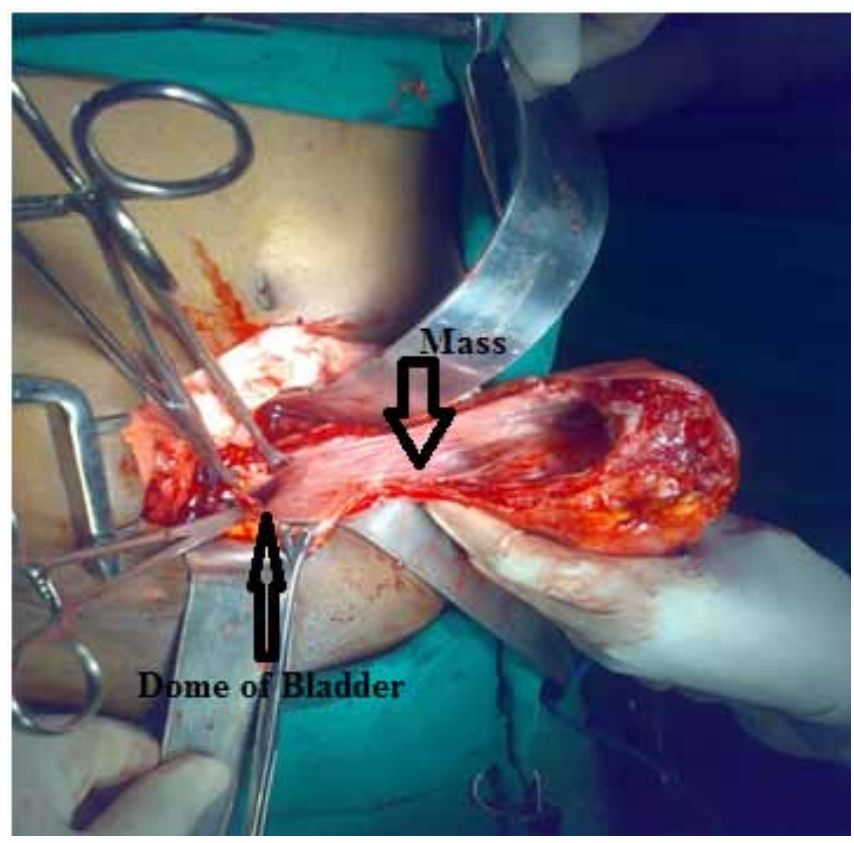

Fig.4: Intraoperative image showing the mass that is communicating with dome of bladder.

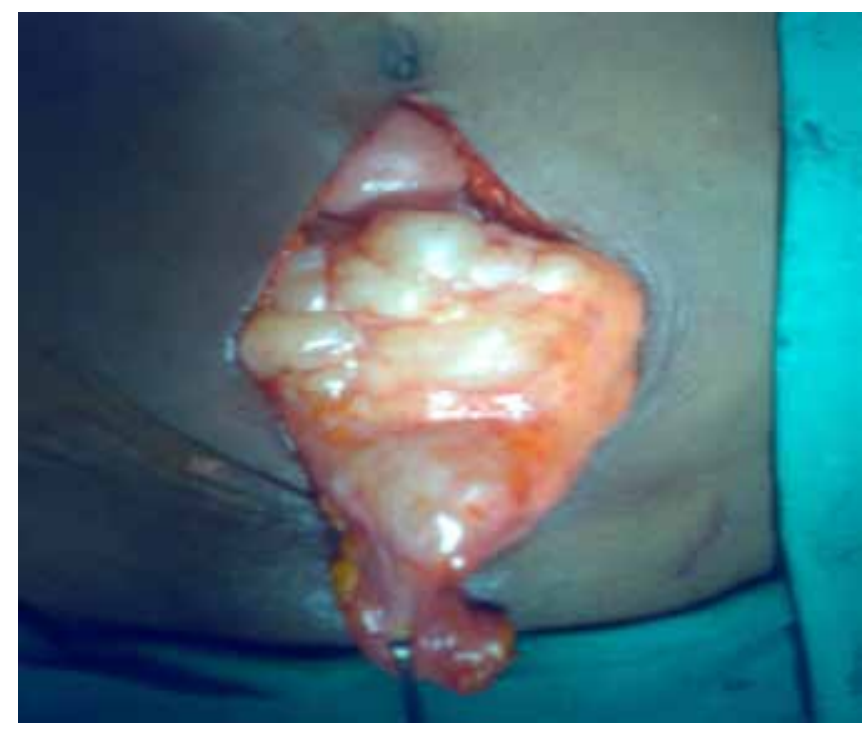

Fig.3: Intraoperative image showing Irregular soft tissue mass with multiple cystic areas on the surface.

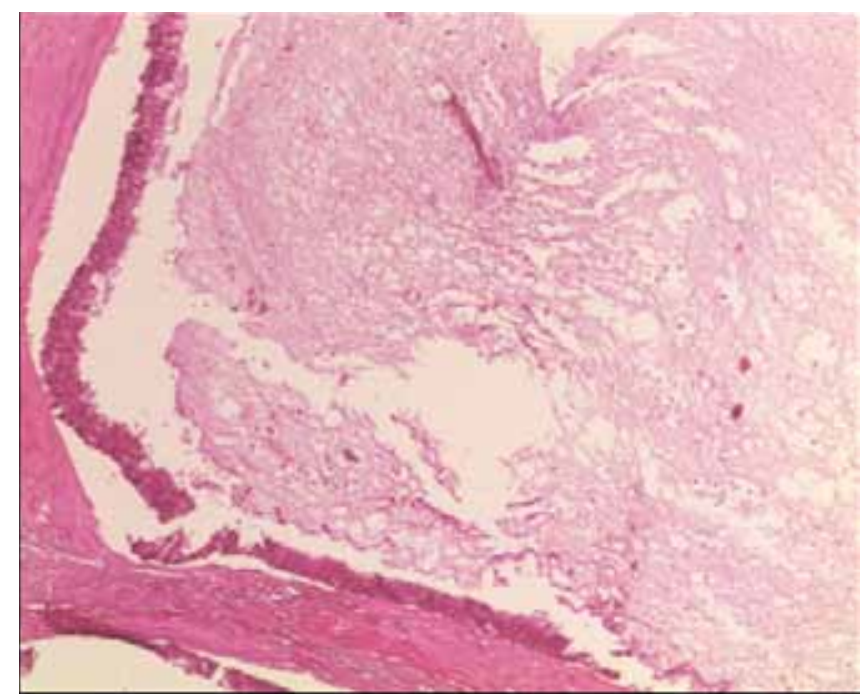

Fig.5: Histopathology showing luminal side of the urachus lined by transitonal epithelium beneath which is loose connective tissue, muscle bundle, fibroareolar tissue at places cysts are lined by columnar epithelium, which show multilayering and moderate degree of atypia. 
undiscovered for a long period because of their obscured location. They can be found incidentally or at an advanced stage. The pathogenesis of urachal tumors is not fully understood. The term mucinous tumor of uncertain malignant potential has been suggested for urachal mucinous tumor without frank invasion. They have a potential for local recurrence and development of pseudomyxoma peritonei. It is believed that urachal carcinomas arise from malignant transformation of columnar or glandular metaplastic epithelium. The differential diagnosis of an urachal mass is extensive and includes both neoplastic and non-neoplastic conditions. Rarely, persistence of a patent urachus will account for a supravesical mass. Benign neoplasms of urachus include desmoid tumor, fibroma, leiomyoma, and villous adenoma although the later may be associated with foci of displasia, adenocarcinoma insitu, or frankly invasive adenocarcinoma [5]. Malignant neoplasm's are urachal mucinous adenocarcinoma, urothelial malignancy with components of adenocarcinoma, and metastatic mucinous tumor from a variety of body sites including breast, pancreas, ovary, prostate gland, and gastrointestinal tract. Criteria to classify a tumor as urachal in origin are as follows: (i) presence of urachal remnants, (ii) tumor growth in the bladder wall and (iii) in the dome of urinary bladder, (iv) $a b \neg$ sence of dysplastic intestinal metaplasia or dysplastic mucosal change, and ( $v$ ) exclusion of other primary malignancies.

We described a rare, mucinous cyst adenoma of undetermined malignant potential of urachus that lacked the architectural features of adenoma and lacked any evidence of destructive stromal invasion to suggest an invasive neoplastic process. To the best of our knowledge, this is the first reported case in India and the seventh case in the English literature. The mucinous cyst adenoma of undetermined malignant potential neither associated with mucin extravasation into perivesical soft tissue nor associated with pseudomyxoma peritonei $[6,7]$.
Despite the absence of invasion all urachal tumours have, the potential for aggressive clinical behavior including local tumor recurrence and complete surgical excision is of para mount importance. As mucinous tumors of the urothelial tract, including those of urachus, may demonstrate aggressive clinical behavior, patients should be followed clinically post excision for evidence of local disease recurrence.

\section{Conclusion}

Mucinous cyst adenoma of undetermined malignant potential of urachus is a rarest histological variety clinical presentation and may demonstrate aggressive clinical behaviour so patients require follow up post operatively for evidence of local recurrence.

\section{References}

1. Schell AJ, Nickel CJ, Phillip A. Isotalo, Complex mucinous cystadenoma of undetermined malignant potential of the urachus Can Urol Assoc J 2009;3(4):E39-E41.

2. Sheldon CA, Clayman RV, Gonzalez R, et al. Malignant urachal lesions. J Urol 1984;131:1-8.

3. Hull MT, Warfel KA. Urachal cystadenoma with abundant glycogen: ultrastructural Study. Ultrastruct Pathol 1994; 18:499-502.

4. Eble JN. Abnormalities of the urachus. In:Young $\mathrm{RH}$, ed. Pathology of the urinary bladder. New York: Churchill Livingstone; 1989. pp. 213-243.

5. De Bree E, Witkamp A, Van De Vijver $M$, et al. Unusual origins of pseudomyxoma peritonei. J Surg Oncol 2000; 75:270-274.

6. Carr NJ, McLean AD. A mucinous tumour of the urachus: adenoma or low grade mucinous cystic tumour of uncertain malignant potential Adv Clin Path 2001 ; 5:93-97.

7. Seibel JL, Prasad S, and Weiss RE, et al. Villous adenoma of the urinary tract: a lesion frequently associated with malignancy. Hum Pathol. 2002; 33:236-241. 